\title{
Hip Disability - A Cross Sectional Study of Prevalence and Characteristics
}

\author{
Maria Klassbo*, Fredrik Lundin \\ Centre for Clinical Research, Varmland County Council, Karlstad, Sweden
}

Received: September 07, 2015; Accepted: October 30, 2015; Published: December 15, 2015

*Corresponding author: Maria Klassbo, Varmland County Council, Sundsgatan 1, SE-661 81 Saffle,Sweden, Tel: +46 533-812 17 ; E-mail: maria.klassbo@liv.se

\begin{abstract}
Hip disability, including pain, stiffness and weakness, can substantially influence people's daily life. To promote and maintain health, physical activity of a certain degree is needed. The purpose of the present study was to estimate the prevalence of hip disability in 18-84 year-olds and to characterise them by sex, age, body mass index (BMI), and physical activity.
\end{abstract}

A postal survey questionnaire was sent to a sample of 11900 subjects in a Swedish county and it was answered by 6475 (response rate 55\%). Main outcome measure was hip disability. Both unadjusted and adjusted regression analysis were used to analyse the relationship between age, BMI and hip disability separately for men and women.

Hip disabilities were reported by $29.9 \%$, more often by women and elderly. Also people $<50$ years reported hip disability (19.8\%). People with hip disability had higher BMI (mean (standard deviation) 27.3 (5.1) and for those without 25.9 (4.7), $p<0.001$ ) and were less physically active $(\mathrm{p}<0.001)$. The association between hip disability and female sex (odds ratio=1.39), became even stronger when adjusting for age and BMI (odds ratio=2.64).

Hip disability is common in the general population. People with hip disability have higher BMI and lower physical activity which can threaten their health. For people with hip disability effective strategies to promote physical activity, despite pain, for preventing serious health consequences must be developed.

Keywords: Hip disability; Osteoarthritis hip; Prevalence; Exercise

\section{Introduction}

In the World Health Organization's (WHO) International Classification of Functioning, Disability and Health, known as ICF, disability is the negative aspect opposed to functioning [1] Disability is consisting of changes in a person's body functions or structures (impairments), activity limitations and/or participation restrictions. Pain, stiffness and weakness are all categories in the domain body functions and common features of hip disability and hip osteoarthritis (OA) [2]. Pain and stiffness, according to ICF sensation of tightness or stiffness of muscles [1], can only be assessed subjectively whereas weakness can be assessed both subjectively and objectively. ICF classifies health and health-related domains in contrast to the International Classification of Diseases, Tenth Revision (ICD-10) that classifies health conditions (diseases, disorders, injuries, etc).

Hip disability can substantially have impact on both activities and health in general [3]. To promote and maintain health, physical activity for a minimum of 30 minutes, five days/week (moderate intensity), or vigorous intensity aerobic activity for a minimum of 20 minutes, three days/week (or a combination) is recommended [4]. But a large proportion of the adult population is physically inactive so effective strategies to promote physical activity must be developed [5]. On individual basis, physical activity on prescription $\left(\mathrm{PaP}^{\circledR}\right)$ can increase physical activity [6].

BMI based on self-reported height and weight is often biased, due to exaggerated (height) and under-estimated (weight), in varied degrees for both men and women being examined [7]. The differences between self-reported and measured length and weight have been found to be small in a Swedish population though, where length was over-reported by less than $0.5 \mathrm{~cm}$, and weight was under-reported by 1.6-1.8 kg [8].

Hip disability can be caused by many diseases, disorders, injuries, etc, but in adults OA of the hip is the most common cause of hip disability. Hip OA can be classified with a combination of radiographic and clinical criteria or with clinical criteria only [9]. The prevalence of hip OA can range between $0.9 \%$ to $27 \%$, mean $8.0 \%$, heterogeneity due to differences in populations, age and gender distribution, type of radiographs, and diagnostic procedures [10]. Clinically diagnosed hip OA always implies hip disability. Pain, stiffness, and decreased hip muscle strength have been found to be significant explanatory factors for self-reported physical disability in persons with hip OA [11].

The objective of this study was to estimate the prevalence of self-reported hip disability in a sample of 18-84 year-olds from the general population and to characterise this population both totally and separately for men and women, according to age and BMI both in adjusted and unadjusted analyses and by physical activity.

\section{Methods}

A cross-sectional survey was performed in a population sample of 11900 men and women aged 18-84 years during MarchMay 2008, covering 16 municipalities in a county in central, 
western Sweden with 211003 inhabitants, using a postal survey questionnaire with three reminders. The sampling was random after stratification for gender, age group, and municipality. The questionnaire covered health, lifestyle factors, living conditions, service in the home municipality and hip disability. A total of $6475 / 11900$ subjects answered the questionnaire with the overall response rate of $55 \%$.

Focus in this study was the question 'Have you during the last six months experienced any problems from one or both of your hips?' [12], answered by 6344/11900 (53\%), followed by “If yes, how would you like to describe your hip problems?" with the alternatives pain, stiffness, weakness and other problems. The overall response rate was 53\%, lower among younger subjects than older (18-34 years 43\%, 35-64 years $52-66 \%$, 65-84 years $61-72 \%$ ), lower among men compared to women (men $51 \%$, women 64\%). There were also differences in education levels (compulsory school 54\%, grammar school 57\%, university 58\%), country of birth (Sweden 59\%, Nordic countries 57\%, other $42 \%)$. Among the responders there were partial missing data on the question regarding self-reported hip disability. Responders had on average a higher physical activity level (PAC), and spent more time per week on moderate physical activity.

BMI was calculated from self-reported weight divided by height squared $(\mathrm{kg} / \mathrm{m} 2)$ categorized according to the World Health Organization guidelines; underweight (BMI $<18.5 \mathrm{~kg} / \mathrm{m} 2)$, normal weight (BMI between 18.5 and $24.9 \mathrm{~kg} / \mathrm{m} 2$ ), overweight (BMI between 25 and $29.9 \mathrm{~kg} / \mathrm{m} 2$ ), and obese (BMI equal to or over $30 \mathrm{~kg} / \mathrm{m} 2$ ) [13].

Physical activity in leisure time, during last 12 months, was estimated on the four-category scale International Physical Activity Questionnaire (IPAQ) [14]. (A) indicated low physical activity (walking, bicycling, or other activities $<2$ hours a week), (B) moderate physical activity (walking, bicycling, or other activities $>2$ hours a week, mostly without perspiring), (C) moderate regular physical activity (physical activity regularly $>30$ minutes, 1-2 times a week changing clothes for running, tennis, bicycling, exercising at a gym, or other physical activity that makes one perspire or increases the pulse rate), and (D) regular physical activity or training (exercising or competing at least three times a week, $>30$ minutes at a time in team sports, jogging, bicycling, aerobics, swimming, or other comparative physical activities, $\geq 3$ times a week).

The question 'How much time do you spend during an ordinary week on moderate activity that makes you warm (walking, gardening, heavy household, bicycling, swimming)? It can vary during the year, but try to make some kind of generalization' was asked with the alternatives; 'at least 5 hours per week', 'more than 3 hours but less than 5 hours per week', 'between 1 and 3 hours per week', and 'less than 1 hour per week'.

\section{Data analysis}

For population characteristics (age, BMI) means and standard deviations (sd) or frequencies (categorical variables) were used. Differences between people with and without hip disability were tested with Mann-Whitney's U-test and Fisher's exact test. Differences in the prevalence of hip disability between age categories were tested with Chi-square test and difference in BMI between age categories using a one-way ANOVA, separately for men and women.

To describe the unadjusted relationship between the prevalence of self-reported hip disability and age and BMI, and the unadjusted relationship between BMI and age, we used a running line smoother [15]. The running line smoother calculated the prevalence of hip disability at each value of age/BMI based on data in a small interval around that value. The results are smooth curves describing how the prevalence varies over age and BMI respectively. To further investigate if differences in prevalence between men and women could be explained by age and BMI, we used logistic regression with sex as analysis variable and adjusted for age and BMI. Non-linear dependencies were investigated using fractional polynomials [15], which is a model for non-linear relationships, flexible enough to capture trends in data, but not too flexible which may lead to over fitting. We also investigated if there were any two-way interactions. Model fit was tested with the Hosmer-Lemeshow test, and coefficient standard errors estimated with the bootstrap method [15]. Based on the regression model we simulated hip disability status based on the predicted probability for hip disability for each subject. By repeating this procedure 1000 times and then using the running line smoother, we were able to construct curves describing the adjusted relationship between hip disability and age and between hip disability and BMI, corresponding to the unadjusted curves [16].

To investigate the possible effect of bias in self-reported BMI we used the algorithm suggested by Nyholm et. al [7]. P-values in table 1 were adjusted using the Bonferroni-Holm method [17]. The analyses were performed with Stata/MP version 13 (Stata Corp LP, College Station, Texas, USA), significance level 0.05 and all two-tailed tests.

\section{Ethical approval}

According to the Swedish law of medical research ethics, population studies with de-identified personal data do not require ethics approval. The respondent has given consent when returning the questionnaire.

\section{Results}

Among the 6344 who (mean age 53 years (sd 18.4)), 1897 (29.9\%) answered that they have had 'hip disability in one or both hips during the last 6 months', more often women and older people (table 1, figure 1).

The prevalence of self-reported hip disability increased up until 70 years of age, both for men and women. After age 70 the prevalence for men levelled out and decreased, but for women it continued to increase with an even steeper slope (figure 1, table 2). People younger than 50 years also reported hip disability (19.8\%). Previously Sundén Lundius et. al [12] have reported the prevalence of self-reported hip disability among people aged 3884. Subjects in that age interval in our study showed a prevalence 
Table 1: Characteristics for Men and Women Separately, for the Whole Sample, and Comparisons between People with and Without Hip Disability.

\begin{tabular}{|c|c|c|c|c|c|c|c|c|c|}
\hline & \multicolumn{3}{|c|}{$\begin{array}{c}\text { Men } \\
\mathrm{n}=2841(44.9 \%)\end{array}$} & \multicolumn{3}{|c|}{$\begin{array}{c}\text { Women } \\
\mathrm{n}=3503(55.1 \%)\end{array}$} & \multicolumn{3}{|c|}{$\begin{array}{c}\text { Total } \\
\mathrm{n}=6344\end{array}$} \\
\hline & \multicolumn{3}{|c|}{ Self-reported hip disability } & \multicolumn{3}{|c|}{ Self-reported hip disability } & \multicolumn{3}{|c|}{ Self-reported hip disability } \\
\hline & $\begin{array}{c}\text { Yes } \\
\mathrm{n}=748 \\
26.3 \%\end{array}$ & $\begin{array}{c}\text { No } \\
\mathrm{n}=2093 \\
73.3 \%\end{array}$ & p-value ${ }^{1}$ & $\begin{array}{c}\text { Yes } \\
\mathrm{n}=1149 \\
32.8 \%\end{array}$ & $\begin{array}{c}\text { No } \\
\mathrm{n}=2354 \\
67.2 \%\end{array}$ & p-value ${ }^{1}$ & $\begin{array}{c}\text { Yes } \\
\mathrm{n}=1897 \\
29.9 \%\end{array}$ & $\begin{array}{c}\text { No } \\
\mathrm{n}=4447 \\
70.1 \%\end{array}$ & p-value ${ }^{1}$ \\
\hline $\begin{array}{l}\text { Age, mean } \\
\text { (sd) }\end{array}$ & $\begin{array}{c}61 \\
(14.8)\end{array}$ & $\begin{array}{c}52 \\
(18.4)\end{array}$ & & $\begin{array}{c}56 \\
(17.0)\end{array}$ & $\begin{array}{c}48 \\
(18.3)\end{array}$ & & $\begin{array}{c}58 \\
(16.4)\end{array}$ & $\begin{array}{c}50 \\
(18.4)\end{array}$ & \\
\hline $\begin{array}{l}\text { BMI, mean } \\
\text { (sd) }\end{array}$ & $27.7(4.5)$ & $26.6(4.5)$ & $<0.001^{2}$ & $27.0(5.5)$ & $25.3(4.7)$ & $<0.001^{2}$ & $27.3(5.1)$ & $25.9(4.7)$ & $<0.001^{2}$ \\
\hline underweight [\%] & 0.5 & 0.7 & & 0.9 & 2.4 & & 0.7 & 1.6 & \\
\hline normal weight [\%] & 25.0 & 37.2 & & 38.9 & 52.2 & & 33.5 & 45.1 & \\
\hline overweight [\%] & 51.8 & 46.0 & & 37.8 & 31.1 & & 43.3 & 38.2 & \\
\hline obese [\%] & 22.7 & 16.2 & & 22.4 & 14.3 & & 22.5 & 15.2 & \\
\hline Pain & 58.7 & 0 & $<0.001^{3}$ & 71.3 & 0 & $<0.001^{3}$ & 66.3 & 0 & $<0.001^{3}$ \\
\hline Stiffness & 39.5 & 12.1 & $<0.001^{3}$ & 55.7 & 18.1 & $<0.001^{3}$ & 48.9 & 15.4 & $<0.001^{3}$ \\
\hline Weakness & 54.4 & 14.5 & $<0.001^{3}$ & 54.7 & 22.4 & $<0.001^{3}$ & 54.6 & 18.9 & $<0.001^{3}$ \\
\hline $\begin{array}{l}\text { Phys activity } \\
\text { level [\%] }\end{array}$ & & & $\mathrm{p}=0.001^{2}$ & & & $\mathrm{p}<0.001^{2}$ & & & $\mathrm{p}<0.001^{2}$ \\
\hline Low & 24.5 & 18.0 & & 21.4 & 14.3 & & 22.6 & 16.1 & \\
\hline Moderate & 42.4 & 39.4 & & 45.2 & 40.9 & & 44.7 & 40.2 & \\
\hline Moderate regular & 18.3 & 24.5 & & 20.7 & 26.1 & & 19.8 & 25.3 & \\
\hline $\begin{array}{l}\text { Regular exercise and } \\
\text { training }\end{array}$ & 14.8 & 18.2 & & 12.8 & 18.7 & & 13.5 & 18.4 & \\
\hline $\begin{array}{c}\text { Moderate phys } \\
\text { activity hrs/week [\%] }\end{array}$ & & & $\mathrm{p}=0.100^{2}$ & & & $\mathrm{p}<0.001^{2}$ & & & $\mathrm{p}<0.001^{2}$ \\
\hline$<1 \mathrm{~h}$ & 15.3 & 10.5 & & 13.3 & 7.9 & & 14.1 & 9.1 & \\
\hline $1-3 \mathrm{~h}$ & 24.8 & 28.0 & & 28.6 & 28.6 & & 27.3 & 28.3 & \\
\hline $3-5 \mathrm{~h}$ & 24.8 & 25.4 & & 29.9 & 32.8 & & 27.9 & 29.2 & \\
\hline$\geq 5 \mathrm{~h}$ & 35.1 & 36.3 & & 22.8 & 30.7 & & 30.9 & 33.4 & \\
\hline
\end{tabular}

Notes. ${ }^{1}$ All p-values are adjusted for mass significance according to the Holm-Bonferroni. ${ }^{2}$ Mann-Whitney's U-test. ${ }^{3}$ Fisher's exact test. Sd $=$ standard deviation.
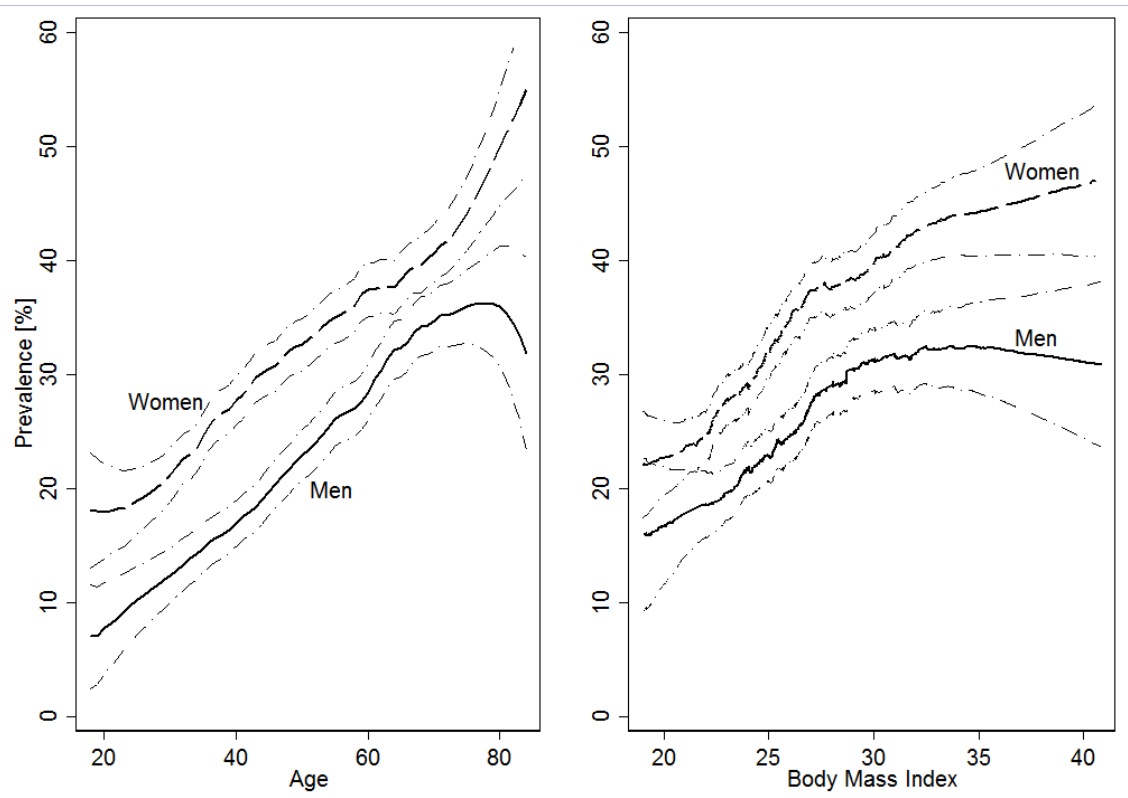

Figure 1: Observed prevalence of hip disability (unadjusted, created with a running line smoother) with $95 \%$ confidence bounds (dash-dotted lines) over age and BMI for men (solid lines) and women (dashed lines) separately. 
Table 2: The Prevalence of Hip Disability, Presented as Numbers and Percentages, in Different Age Groups for Men and Women Separately, for the Whole Sample, and Comparisons with in Groups.

\begin{tabular}{|c|c|c|c|c|c|c|c|c|c|}
\hline & Men & & & Women & & & Total & & \\
\hline & {$[\mathrm{n}]$} & [\%] & p-value ${ }^{1}$ & {$[\mathrm{n}]$} & [\%] & p-value ${ }^{1}$ & {$[\mathrm{n}]$} & [\%] & p-value ${ }^{1}$ \\
\hline Age groups & & & $<0.001^{2}$ & & & $<0.001^{2}$ & & & $<0.001^{2}$ \\
\hline $18-34$ & $51 / 519$ & 9.8 & & $156 / 817$ & 19.1 & & $207 / 1336$ & 15.5 & \\
\hline $35-49$ & $95 / 516$ & 18.4 & & $210 / 718$ & 29.3 & & $305 / 1234$ & 24.7 & \\
\hline $50-64$ & $203 / 722$ & 28.1 & & $322 / 870$ & 37.0 & & $525 / 1592$ & 33.0 & \\
\hline $65-79$ & $353 / 929$ & 38.0 & & $369 / 930$ & 39.7 & & $722 / 1859$ & 38.8 & \\
\hline $80-84$ & $46 / 155$ & 29.7 & & $92 / 168$ & 54.8 & & $138 / 323$ & 42.7 & \\
\hline Total & $748 / 2841$ & 26.3 & & $1149 / 3503$ & 32.8 & & $1897 / 6344$ & 29.9 & \\
\hline
\end{tabular}

Notes. ${ }^{1}$ All p-values are adjusted according to the Holm-Bonferroni method to avoid spurious hypothesis rejection due to mass significance. ${ }^{2} \mathrm{Chi}-$ square test.

of (1 649/4 798) 34\%. Among those with self-reported hip disability $66.3 \%$ reported hip pain, $44.6 \%$ reported stiffness, $9.2 \%$ reported weakness (figure 2) and $7.8 \%$ reported other problems.

When applying the suggested correction algorithm to our material [7], using age as correction factor, the corrected BMI was on average $0.8 \mathrm{~kg} / \mathrm{m}^{2}$ higher than the self-reported. These were small differences and the effect of the correction on our regression analyses was negligible. Since the actual changes in BMI were small, we have chosen to use the self-reported BMI in our analysis.

There were differences in BMI between age categories (1834 yrs 25.3 (sd 5.6), 35-49 yrs 26.3 (sd 4.7), 50-64 yrs 26.8 (sd 4.3), 65-79 yrs 26.7 (sd 4.7), 80-84 yrs 25.8 (sd 5.3), (One-Way ANOVA, $p<0.001)$. There were also differences between men and women in the relation between BMI and age, where men had higher BMI than women up to 75 years of age (figure 3). The prevalence of self-reported hip disability increased with BMI, with higher prevalence for women (figure 1). For men the prevalence increased with BMI only up to BMI 32.
In the adjusted analysis (figure 4), the non-linear association (seen in figure 1) remained only between BMI and self-reported hip disability, but was almost linear corresponding to an odds ratio approximately 1.03 .

There were no significant interactions between explanatory variables, except between sex and age. The odds ratio for age was almost identical for men $(\mathrm{OR}=1.02,95 \% \mathrm{CI}[1.018,1.026]$, $\mathrm{p}<0.001)$ and women (OR=1.03, 95\% CI [1.026, 1.038], $\mathrm{p}<0.001)$. In the regression analysis with sex as the only explanatory variable, women had higher odds for hip disability (odds ratio $(\mathrm{OR})=1.39,95 \%$ confidence interval (CI) $[1.24,1.56], \mathrm{p}<0.001$ ) than men. When adjusting for age and BMI the association became stronger $(\mathrm{OR}=2.64,95 \% \mathrm{CI}[1.20,5.78], \mathrm{p}=0.016)$.

People with hip disability were less physically active (both men and women), compared to people without hip disability (table 1).

\section{Discussion}

Hip disability is common in the general population aged 1884 (29.9\%). People with hip disability were older, more often women, had higher BMI, and were less physically active. The

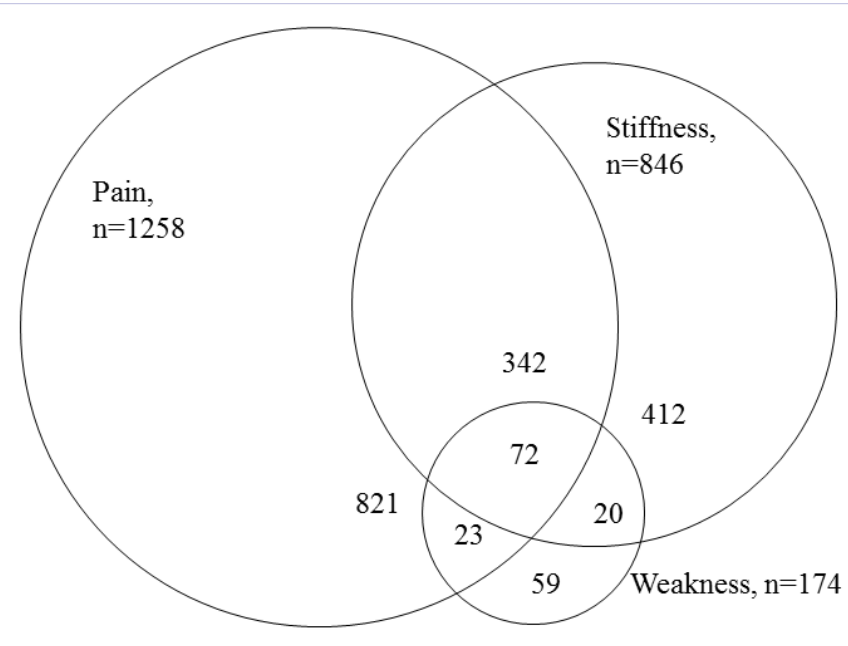

Figure 2: Number of subjects with pain, weakness and stiffness among those with self-reported hip disability. 


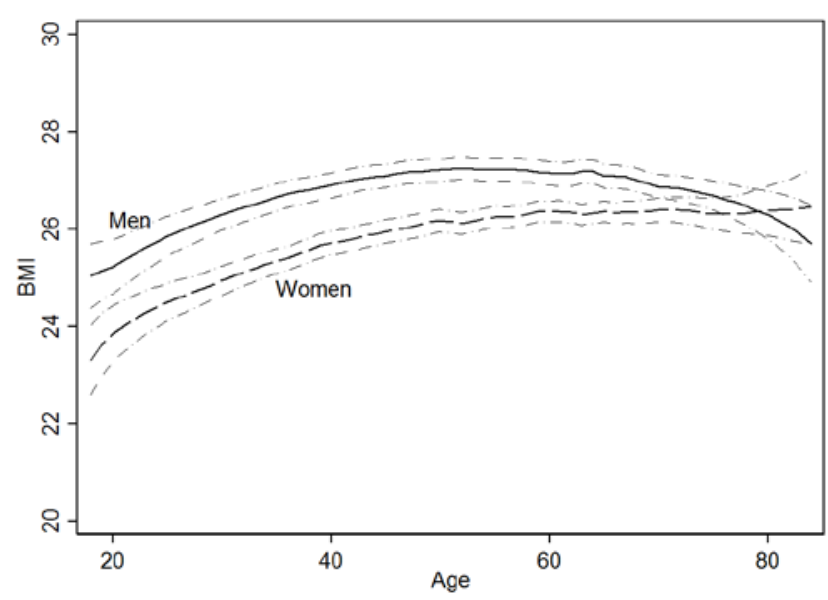

Figure 3: Observed unadjusted mean BMI over age (created with a running line smoother) with $95 \%$ confidence bounds (dash-dotted lines), for men (solid line) and women (dashed line).
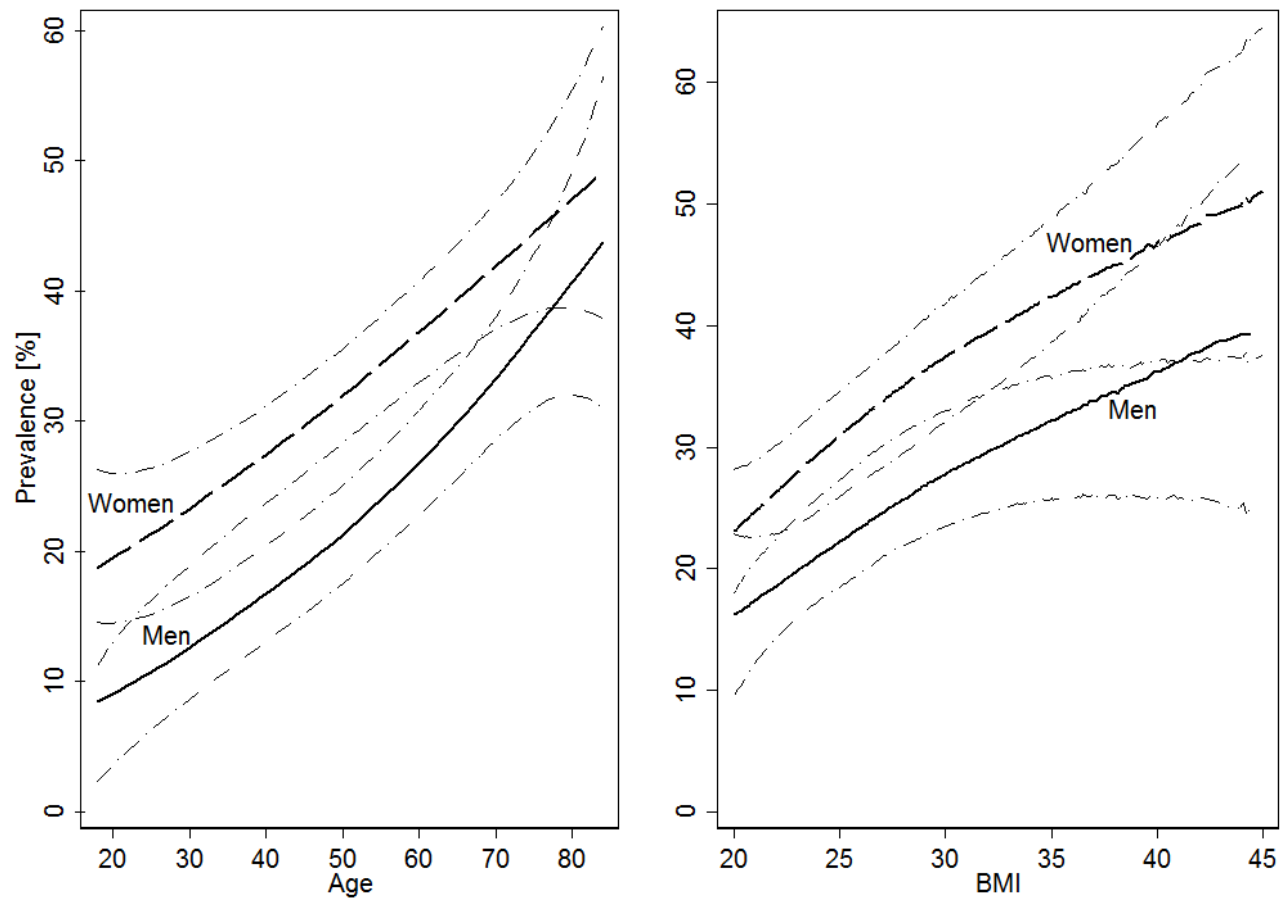

Figure 4: Predicted mean prevalence of self-reported hip disability, with confidence bounds (dash-dotted lines) in different ages, adjusted for BMI (left), and for different BMI, adjusted for age (right), for men solid lines and for women dashed lines.

difference in prevalence of hip disability became even larger, between men and women, after adjustment for age and BMI.

There were differences in the prevalence curves when comparing unadjusted (figure 1) and adjusted analysis (figure 4). The discrepancy may be explained by the difference between men and women in the relationship between age and BMI (figure 3). The BMI levelled out and decreased after 50 years of age for men, but for women it levelled out and stayed almost constant after age 60. For subjects older than 70 years the BMI was approximately the same for men and women.

Strength of the study is that it is population based in contrast to studies where the study group is recruited from the healthcare system. A weakness is the low response rate, $53 \%$.

Compared to a population-based study in the south of Sweden with people between 38-77 years (where the same questions concerning hip disability, although translated to hip 
disorder, were used [12], ), we found in our study almost the same prevalence, $34 \%$ compared to $32 \%$ in their study.

Hip OA is the most common disorder causing hip disability. But we don't know anything about the prevalence of hip OA in this study and we did not ask for previous diagnosis of hip OA. In a cross sectional survey of people aged $\geq 40$ years $(n=195)$, mean age 63 years, presenting with a new episode of hip pain recruited from general practitioners in UK, $44 \%$ had evidence of radiographic change [3]. In our sample the mean age for people with hip disability was lower, 58 years, so radiological evidence of hip OA should be $<44 \%$.

People with hip disability in this study, were less physically active compared to those without hip disability. Information about physical activity (not too much and not too little), exercise and weight control, leading to better self-management, delivered as OA schools $[18,19]$ have together with $\mathrm{PaP}^{\circledR}$ (and other physical activity enhancing tools) the potential to prevent and reduce pain, stiffness and weakness [18], lowering the risk of anxiety and depression [20], and lowering the risk of inactivity induced illness and premature death [21]. Exercise may also have metabolic effects influencing OA progression, including suppression of inflammation and catabolic activity, enhancing anabolic activity, and maintaining metabolic homeostasis [22] and can also improve the GAG content in the cartilage [23]. Leisure time with physical activity can prevent end-stage OA [24] and one study has suggested that exercise therapy in addition to patient education can, at least, postpone the need for THR in patients with hip OA [25]. When people with hip disability visit health care services, they should be referred to OA schools, unless the disability is caused by other diseases, disorders, or injuries than hip OA.

Further studies are needed to develop effective strategies to help people to prevent hip disability and when it is present, promote physical fitness to reduce the risk of serious health consequences [26].

Hip disability is common in the general population. People with hip disability have higher BMI and lower physical activity which can threaten their health.

\section{Acknowledgements}

Thanks to Marina Kalander Blomqvist for acquisition of data and to Pia Hird for reviewing our English. MK and FL were supported by the Centre for Clinical Research, Värmland County Council.

\section{References}

1. World Health Organization. International Classification of Functioning, Disability and Health. 2001;Available from:http://www.who.int/ classifications/icf/icf_more/en/.

2. Klässbo M, Larsson E, Mannevik E. Hip disability and osteoarthritis outcome score. An extension of the Western Ontario and McMaster Universities Osteoarthritis Index. Scand J Rheumatol. 2003;32(1):4651.

3. Birrell F, Croft P, Cooper C, Hosie G, Macfarlane G, Silman A, et al. Health impact of pain in the hip region with and without radiographic evidence of osteoarthritis: a study of new attenders to primary care. Ann Rheum Dis. 2000;59: 857-863.

4. Nelson ME, Rejeski WJ, Blair SN, Duncan PW, Judge JO, King AC, et al. Physical activity and public health in older adults: Recommendation from the American College of Sports Medicine and the American Heart Association. Med Sci Sports Exerc. 2007;39(8):1435-1445.

5. Hellénius ML. Prescribing exercise in clinical practice. Curr Cardiovasc Risk Reports. 2011;5:331-339.

6. Kallings LV, Leijon M, Hellenius ML, Stahle A. Physical activity on prescription in primary health care: a follow-up of physical activity level and quality of life. Scand J Med Sci Sports. 2008;18(2):154-161.

7. Connor Gorber S, Tremblay M, Moher D, Gorber B. A comparison of direct vs. self-report measures for assessing height, weight and body mass index: a systematic review. Obesity Rev. 2007;8(4):307-326.

8. Nyholm M, Gullberg B, Merlo J, Lundqvist-Persson C, Råstam L, Lindblad $U$. The validity of obesity based on self-reported weight and height: Implications for population studies. Obesity. 2007;15(1):197208.

9. Altman R, Alarcón G, Appelrouth D, Bloch D, Borenstein D, Brandt $\mathrm{K}$, et al. The American College of Rheumatology criteria for the classification and reporting of osteoarthritis of the hip. Arthritis Rheum. 1991;34(5):505-514.

10. Dagenais S, Garbedian S, Wai EK. Systematic review of the prevalence of radiographic primary hip osteoarthritis. Clin Orthop Rel Res. 2009;467(3):623-637. doi: 10.1007/s11999-008-0625-5.

11. Steinhilber B, Haupt G, Miller R, Grau S, Janssen P, Krauss I, et al. Stiffness, pain, and hip muscle strength are factors associated with self-reported physical disability in hip osteoarthritis. J Geriatr Phys Ther. 2014;37(3):99-105. doi: 10.1519/JPT.0b013e3182abe7b5.

12. Sundén-Lundius A. Johnsson B, Lohmander S, Ekdahl C. Prevalence of self-reported hip disorders, relations to age, gender, pain, stiffness, weakness and other joint disorders. Adv Physiother. 2005;7(3):108113.

13. World Health Organization. Obesity-and overweight. 2006;Available at: http://www.who.int/mediacentre/factsheets/fs311/en/http:// www.who.int/mediacentre/factsheets/fs311/en/index.html.

14. Ekelund U, Sepp H, Brage S, Becker W, Jakes R, Hennings M, et al. Criterion-related validity of the last 7-day, short form of the International Physical Activity Questionnaire in Swedish adults. Pub Health Nutr. 2006;9(2):258-265.

15. Royston P, Sauerbrei P. Multivariable model-building: A pragmatic approach to regression analysis based on fractional polynomials for modelling continuous variables. Hoboken: John Wiley \& Sons. 2008.

16. Breiman L. Bagging predictors. Machine Learning. 1996;24(2):123140.

17. Holm, S. A simple sequentially rejective multiple test procedure. Scand J Statistics. 1979;6:65-70.

18. Klässbo M, Larsson G, Harms-Ringdahl K. Promising outcome of a Hip School for patients with hip dysfunction. Arthritis Rheum. 2003;49(3):321-327.

19. Thorstensson CA, Garellick G, Rystedt GH, Dahlberg LE. Better management of patients with osteoarthritis: Development and nationwide implementation of an evidence-based supported osteoarthritis self-management programme. Musculoskeletal Care. 2015;13(2):67-75.. doi: 10.1002/msc.1085. 
20. Teychenne M, Ball K, Salmon J. Physical activity and likelihood of depression in adults: A review. Prev Med. 2008;46(5):397-411. doi: 10.1016/j.ypmed.2008.01.009.

21. Nüesch E, Dieppe P, Reichenbach S, Williams S, Iff S, Jüni P, et al. All cause and disease specific mortality in patients with knee or hip osteoarthritis: population based cohort study. BMJ. 2011;342: d1165.

22. Leong DJ, Sun HB. Osteoarthritis - Why exercise?. J Exerc Sports Orthop. 2014;1(1):1-3.

23. Roos EM. Dahlberg L. Positive effects of moderate exercise on glycosaminoglycan content in knee cartilage: a four-month, randomized, controlled trial in patients at risk of osteoarthritis Arthritis Rheum. 2005;52(11):3507-3514.

24. Ageberg E, Engström G, Gerhardsson de Verdier M, Rollof J, Roos EM,
Lohmander SL. Effect of leisure time physical activity on severe knee or hip osteoarthritis leading to total joint replacement: a populationbased prospective cohort study. BMC Musculoskeletal Disorders. 2012;13:73.

25. Svege I, Nordsletten L, Fernandes L, Risberg MA. Exercise therapy may postpone total hip replacement in patients with hip osteoarthritis: a long-term follow-up of a randomized trial. Ann Rheum Dis. 2015;74:164-169. doi:10.1136/annrheumdis-2013-203628.

26. Ekelund U, Ward HA, Norat T, Luan J, May AM, Weiderpass E, et al. Physical activity and all-cause mortality across levels of overall and abdominal adiposity in European men and women: the European Prospective Investigation into Cancer and Nutrition Study (EPIC). Am J Clin Nutrition. 2015;101:613-621. 